\title{
KONSERVASI PLASMA NUTFAH SALAK SEBAGAI KEBUN BOTANI UNTUK MENDUKUNG DESA SIBETAN SEBAGAI DESA SENTRA AGROWISATA BERBASIS SALAK
}

\author{
I N. Rai ${ }^{1}$, I P. Sudana ${ }^{2}$, W. Wiraatmaja ${ }^{3}$, dan Made Sukewijaya ${ }^{4}$
}

\begin{abstract}
ABSTRAK
Desa Sibetan yang terletak di Kecamatan Bebandem Karangasem, telah terkenal sebagai sentra penghasil salak di Bali. Tanaman salak sudah diusahakan secara turun-temurun oleh hampir semua penduduk dan sudah tentu telah menjadi bagian penting bagi perekonomian dan kesejahteraan masyarakat. Disamping terkenal dengan ikon salaknya, Desa Sibetan juga memiliki panorama alam yang indah, udara sejuk dan segar, aksesibilitasnya mudah dicapai, dan memiliki berbagai jenis keanekaragaman hayati salak sehingga sangat potensial dikembangkan sebagai obyek agrowisata berbasis salak. Kegiatan pengabdian dengan skim Program Pengembangan Desa Mitra (PPDM) ini dilakukan untuk mengidentifikasi dan mengkoleksi plasma nutfah salak yang ada di Desa Sibetan, kemudian dikonservasi menjadi Kebun Botani plasma nutfah untuk mendukung Desa Sibetan sebagai obyek agrowisata berbasis salak. Kegiatan dilakukan dari April 2017September 2018, menggunakan pendekatan masyarakat sasaran diajak berkerja bersama-sama (working with community) dan bekerja sambil belajar (learning by doing) melalui penerapan metode Entrepreneurship Capacity Building (ECB) dan Technology Transfer (TT). Jenis kegiatan yang dilakukan yaitu identifikasi dan koleksi keragaman kultivar plasma nutfah salak, pelatihan dan transfer teknologi pembuatan bibit, penanaman hasil koleksi menjadi kebun botani plasma nutfah (arboretum), dan pemeliharaan arboretum dengan menerapkan Good Agricultural Practices/GAP. Dari kegiatan telah berhasil diidentifikasi dan dikoleksi 12 jenis plasma nutfah salak yang ada Desa Sibetan, yaitu Salak Bingin, Gondok, Getih/Merah, Gula Pasir, Injin, Kelapa, Nangka, Nenas, Pade, Penyalin, Turis/Mangku, dan Sudamala. Bibit salak hasil koleksi dikonservasi dalam satu areal khusus menjadi kebun botani plasma nutfah atau arboretum, kemudian dipelihara dengan menerapkan cara budidaya yang baik dan benar bersama peserta.
\end{abstract}

Kata kunci: agrowisata, arboretum, PPDM, salak, Sibetan.

\begin{abstract}
The rapid development of tourism in Bali has not been synergistic with the agricultural sector, even the polemic develops that rapid growth of tourism actually causes the increasingly aggravated of agricultural sector. To avoid unbalanced development between tourism and agriculture it's developed model of agricultural integrated with tourism. Sibetan village which is famous as a center of salak production, has a beautiful natural scenery, fresh air, and has a large biodiversity of salak so that very potential to be developed as an agro-tourism destination base on salak. This community service aimed to identify and collect salak germplasm in Sibetan Village, then to be conserved into a botanical garden (arboretum) to support Sibetan Village as an agro-tourism salak-based. The activities were conducted during 6 months from April 2017 to September 2018. Implementation of activities used approach working with target communities and learning by doing through application of Entrepreneurship Capacity Building (ECB) and Technology Transfer (TT) method. The types of activities carried out were identification and collection of salak germplasm, training and technology transfer for seedling, planting of salak germplasm into germplasm botanical garden or arboretum, and maintenance of arboretum by applying good agricultural practices. Through this community service has been identified and collected 12 types of salak germplasm in Sibetan Village. All of them were Bingin, Gondok, Getih/Merah, Bula Pasir, Injin, Kelapa, Nangka, Nenas, Pade, Penyalin, Turis/Mangku, and Sudamala. The seedling planted and conserved in a special area into arboretum, then maintained by applying good agricultural practices with the participants.
\end{abstract}

${ }^{I}$ Staf Pengajar Prodi Agroekoteknologi, Fakultas Pertanian, Universitas Udayana; rainyoman@unud.ac.id

${ }^{2}$ Staf Pengajar Prodi Industri Perjalanan Wisata, Fakultas Pariwisata, Universitas Udayana, Denpasar

${ }^{3}$ Staf Pengajar Prodi Agroekoteknologi, Fakultas Pertanian, Universitas Udayana

${ }^{4}$ Staf Pengajar Prodi Agroekoteknologi, Fakultas Pertanian, Universitas Udayana 
Keywords: agrotourism, arboretum, PPDM, salak, Sibetan.

\section{PENDAHULUAN}

Desa Sibetan yang terletak di Kecamatan Bebandem Karangasem, telah terkenal sebagai sentra penghasil salak di Bali. Tanaman salak sudah diusahakan secara turun-temurun oleh hampir semua penduduk dan tentu telah menjadi bagian penting bagi perekonomian dan kesejahteraan masyarakat di desa tersebut. Disamping terkenal dengan ikon salaknya, Desa Sibetan juga memiliki panorama alam yang indah, udara sejuk dan segar, aksesibilitasnya mudah dicapai, dan lokasinya dekat dengan berbagai destinasi wisata yang telah berkembang seperti Besakih, Candidasa, Taman Ujung Karangasem, Tirtagangga, dan lain-lain, sehingga sangat potensial dikembangkan sebagai obyek agrowisata berbasis salak (Rai et al., 2018).

Pengembangan agrowisata berbasis salak di Desa Sibetan sangat penting mengingat dampak dari pembangunan Bali yang dominan menggenjot sektor pariwisata menyebabkan terpusatnya investasi hanya ke sektor tersebut di wilayah perkotaan dan pusat-pusat kegiatan pariwisata, sedangkan daerah pedesaan yang kental dengan sektor pertanian kurang mendapatkan manfaat. Perkembangan yang asimetris antara pariwisata dan pertanian menyebabkan kontribusi sektor pariwisata terhadap PDRB Bali selama tiga tahun terakhir meningkat signifikan yaitu dari $23,14 \%$ pada tahun 2015 menjadi $25,27 \%$ pada tahun 2017 , sementara kontribusi sektor pertanian pada periode yang sama semakin menurun dari 14,65\% pada tahun 2015 menjadi 14,35\% pada tahun 2017 (BPS Bali, 2018). Melalui pengembangan agrowisata diharapkan ada dampak langsung dan aliran dana dari pariwisata kepada petani di pedesaan dengan adanya transaksi ekonomi antara masyarakat petani sebagai komunitas desa dengan para wisatawan (Asosiasi Wisata Agro Indonesia, 2004; Departemen Pertanian, 2008). Dengan demikian, kedepan sektor primer (pertanian) tidak semakin terpinggirkan dan ditingglkan (Sumarwoto, 1990; Goodwin, 2008), tetapi sebaliknya semakin berkembang karena mendapatkan nilai tambah dari sentuhan sektor pariwisata (Rai et al., 2017).

Potensi agrowisata salak Sibetan tidak hanya sebatas sebagai sentra produksi dalam arti kuantitas, kualitas dan beranekaragamnya produk olahan dari salak yang dihasilkan, tetapi juga menyangkut tingginya diversitas sumberdaya genetik plasma nutfah salak yang ada. Namun, potensi besar yang dimiliki belum digarap dengan baik sehingga perkembangan pariwisata yang pesat di Bali belum dirasakan manfaatnya oleh masyarakat Desa Sibetan. Pada aspek on-farm, petani dan masyarakat Sibetan belum mampu mengkemas berbagai potensi yang dimiliki menjadi something to see (sasuatu yang dapat dilihat), something to do (sesuatu yang dapat dikerjakan), something to buy (sesuatu yang dapat dibeli), something to learn (sesuatu yang dapat dipelajari), dan something to share (sesuatu yang dapat di-share) oleh wisatawan (Rai et al., 2018). Terkait dengan hal tersebut, kegiatan ini bertujuan mengidentifikasi dan mengkonservasi keragaman plasma nutfah salak Desa Sibetan sebagai kebun botani untuk mendukung Desa Sibetan sebagai desa sentra agrowisata berbasis salak.

Varietas salak dibedakan berdasarkan beberapa kriteria seperti tekstur daging buah, warna kulit buah, warna daging buah, rasa dan aroma daging buah, besar buah, morfologi daun, warna bunga, dan habitus (Annisaurrohmah et al., 2014; Rai et al., 2016a). Perbedaan kultivar tidak hanya bisa terjadi pada tanaman salak dari sentra produksi yang berbeda, tetapi juga antar tanaman dalam satu daerah yang sama karena adanya perbedaan genetik dan faktor lingkungan serta akibat adanya mutasi dan penyerbukan silang (Suskendriyati et al., 2000; Ariestin et al., 2015; Pulakiang et al., 2017). Plasma nutfah salak yang beraneka ragam yang terdapat di Desa Sibetan dapat digunakan untuk mendukung pengembangan agrowisata dengan melakukan konservasi dalam satu kawasan dalam bentuk kebun botani plasma nutfah atau arboretum. Menurut Rai et al. (2016b), integrasi pertanian dan pariwisata di Bali yang berbasis buah-buahan sangat menonjol antara lain tercermin dari pemanfaatan buah-buahan untuk konsumsi wisatawan dan untuk bahan massage/Spa (solus per aqua), serta pemanfaatan kebun buah-buahan sebagai obyek agrowisata.

Konservasi sumberdaya genetik adalah pemeliharaan dan perlindungan sumberdaya genetik secara teratur bertujuan untuk mencegah kerusakan dan kemusnahan serta menjamin kontinyuitas keberadaan habitat/populasi, evolusi dan adaptabilitas dari sumberdaya genetik (Nandini dan Shiddamallayya, 2015). Konservasi sumberdaya genetik dapat dilakukan secara in situ dan ex situ. Koservasi in situ dilakukan secara alami pada habitat asal atau dengan cara dikelola oleh masyarakat dengan tujuan untuk melestarikan dan memanfaatkan produk dari tanaman tersebut atau disebut juga dengan on farm conservation. Sedangkan konservasi ex-situ dilakukan di luar habitat asalnya, dapat dilakukan di lapang, di rumah kaca, atau di laboratorium secara in vitro (Purnamo et al., 2015; Nandini dan Shiddamallayya, 2015). 


\section{Konservasi Plasma Nutfah Salak Sebagai Kebun Botani Untuk Mendukung Desa Sibetan Sebagai Desa Sentra Agrowisata Berbasis Salak}

Kegiatan konservasi sumberdaya genetik salak Sibetan dalam bentuk arboretum disatu sisi dimaksudkan untuk melestarikan jenis-jenis salak yang yang ada dan disisi lain arboretum yang dibangun dapat dimanfaatkan sebagai obyek agrowisata untuk meningkatkan taraf hidup petani salak dan masyarakat Desa Sibetan. Selain memiliki manfaat langsung (tangible) sebagai penghasil buah, arboretum salak juga memiliki manfaat tidak langsung (intangible), yaitu terbentuknya iklim mikro dan suasana yang cocok untuk dijadikan kawasan agrowisata. Menurut Napolion et al. (2015) dan Annisa et al. (2017), arboretum adalah kebun koleksi dengan luasan tertentu berisi berbagai jenis ditanam dengan kondisi lingkungan mengikuti habitat aslinya, berperan sebagai areal pelestarian keanekaragaman hayati, sarana pendidikan/edukasi, penelitian, dan wisata/rekreasi alami. Keberadaan arboretum dimaksudkan juga untuk meningkatkan pemahaman masyarakat tentang kultivar lokal yang ada untuk menunjang keberhasilan kegiatan on farm conservation, karena pemahaman suatu kultivar adalah salah satu kunci dari keberhasilan konservasi sehingga petani dapat mengambil manfaat serta keuntungan dari kultivar yang ditanamnya, dan mereka akan terus memelihara dan mengembangkan kultivar lokal yang bersangkutan (Subbaraya 2006; Yudohartono, 2008).

\section{METODE PELAKSANAAN}

Kegiatan pengabdian dengan skim Program Pengembangan Desa Mitra (PPDM) dana Ristekdikti ini dilakukan di Desa Sibetan, Kecamatan Bebandem, Kabupaten Karangasem, dari April 2017 sampai September 2018. Jenis kegiatan terdiri atas: (1) identifikasi dan koleksi keanekaragaman kultivar plasma nutfah salak, (2) pelatihan dan transfer teknologi pembuatan bibit, dan (3) penanaman bibit hasil koleksi dan pemeliharaan arboretum dengan menerapkan cara budidaya yang baik dan benar (Good Agricultural Practices/GAP). Metode pelaksanaan pengabdian menggunakan pendekatan masyarakat sasaran diajak berkerja bersama-sama (working with community) dan bekerja sambil belajar (learning by doing) melalui penerapan metode Entrepreneurship Capacity Building (ECB) dan Technology Transfer (TT). Metode ECB dan $T T$ dilakukan untuk meningkatkan pemahaman peserta tentang pentingnya plasma nutfah salak yang dimiliki serta manfaat arboretum salak sebagai obyek agrowisata.

Tahapan identifikasi dan koleksi keanekaragaman kultivar plasma nutfah salak diawali dengan pengumpulan informasi tentang jenis-jenis sumberdaya genetik/kulitivar salak yang ada di Desa Sibetan menyangkut nama kultivar dan lokasi keberadaannya. Berdasarkan informasi tersebut dilakukan survei untuk menemukan kultivar yang dimaksud kemudian dilakukan identifikasi jenis (famili, genus, spesies, nama Lokal Bali, nama Indonesia, nama Latin dan nama Inggris), indentifikasi karakter morfologi (tekstur daging buah, warna kulit buah, warna daging buah, rasa dan aroma daging buah, besar buah, morfologi daun, warna bunga, dan habitus), dan pengambilan biji dan foto tanaman. Berdasarkan data berbagai kultivar yang ditemukan kemudian dilakukan koleksi dan pengenalan keankaragaman kultivar salak yang terdapat di Desa Sibetan.

Lokasi pembuatan bibit dilaksanakan di salah satu kebun Milik Petani di Banjar Karanganyar, Desa Sibetan, Karangasem, Bali. Pembibitian dilaksanakan oleh tim pengabdian PPDM bersama anggota Kelompok Tani Kertha Semaya, Desa Sibetan, dan dibantu oleh mahasiswa KKN-PPM Universitas Udayana Periode Juli Tahun 2018. Pelaksanaan pembuatan bibit disertai dengan pelatihan dan transfer teknologi dengan kelompok sasaran/perserta adalah anggota Kelompok Tani Kerta Semaya, Sibetan. Proses pelaksanaan pembuatan bibit dilakukan melalui metode bekerja sambil belajar pada semua tahapan proses pembibitan yaitu pemilihan buah yang baik sebagai sumber benih, pemilihan lokasi pembibitan, penyiapan alat-alat dan bahan pembibitan, pembuatan rumah pembibitan, penyiapan polibag dengan campuran tanah, pasir dan pupuk kandang, penyemaian benih, penanaman benih, dan pemeliharaan bibit dengan menerapkan cara budidaya yang baik dan benar (Good Agricultural Practices/GAP) meliputi penyiraman, pemupukan, pengendalian gulma, dan pemberantasan hama dan penyakit), dan pengairan.

Bibit koleksi hasil perbanyakan ditanam dalam lokasi khusus seluas satu hektar di Banjar Karanganyar, Desa Sibetan, Karangasem, Bali, yang telah disiapkan oleh Kelompok Tani Kertha Semaya untuk kebun botani plasma nutfah salak. Pelaksanaan penanaman bibit dan pemeliharaan Arboretum juga melibatkan anggota kelompok tani melalui bekerja sambil belajar pada semua tahapan proses kegiatan. Pada tahapan ini peserta diberikan pemahaman secara teoritis dan praktis tentang cara penanaman dan budidaya secara baik dan benar, kemudian diikuti dengan memberikan contoh dan praktek langsung dikerjakan bersama-sama oleh intruktur (tim pengabdian) dan anggota Kelompok Tani Kerta Semaya. Metode tersebut diterapkan dengan harapan peserta memiliki pengetahuan yang benar sekaligus mempu mengimplementasikan secara tepat dan 
efektif.

\section{HASIL DAN PEMBAHASAN}

Berdasarkan hasil survei dan identifikasi, salak yang ada di Desa Sibetan dari klasifikasi botani tergolong familia palmae, genus Salacca, spesies Salacca edulis Reinw., nama latin Salacca Zalaca, nama Indonesia salak, nama lokal Bali salak, dan nama Inggris snake fruit. Secara morfologi tumbuhnya tegak dengan batang pendek, daunnya berpelepah, bertulang sejajar, pada pelepah daun terdapat anak daun (leaflets), dan bentuk daunnya seperti kipas. Kultivar yang ditemukan berjumlah 12 jenis yaitu:

1. Salak Bingin (Salacca zalacca var. Bingin). Salak bingin habitusnya pendek dengan tinggi kurang dari $1 \mathrm{~m}$, pelepahnya kekar tetapi pendek, jarak antar pelepah rapat, dan dadaunan rimbun sehingga tutupan tajuk mirip seperti pohon beringin. Dari namanya mungkin dibayangkan bahwa salak ini besar dan rindang seperti pohon beringin, tetapi sejatinya salak ini kecil dan daunnya agak keriting, tetapi tipe tutupan tajuknya menyerupai beringin sehingga disebut salak Bingin. Lebih cocok disebut bahwa kultivar ini tergolong kultivar unik karena ukurannya kecil dan sifatnya berbeda dengan kultivar salak lainnya yaitu sangat jarang berbuah. Kultivar ini cocok dipakai sebagai bonsai.

2. Salak Gondok (Salacca zalacca var. Gondok). Salak Gondok merupakan salak yang paling banyak diusahakan di Desa Sibetan. Bentuk buahnya agak bulat dengan pangkal meruncing, warna kulit buah coklat dan pada dasar buah terdapat semburat merah, jika dikupas daging buahnya putih kekuningan. Biji kecil, daging buahnya tebal dan tidak melekat pada biji, rasanya manis, getas dan berair. Bila buah masak digoyangkan akan terdengar bunyi seperti batu bergerak didalam buah salak Gondok ini.

3. Salak Getih/Merah (Salacca zalacca var. Getih). Salak Getih memiliki ciri khas kulit buah agak kehitaman dibagian ujung, jika dikupas pada daging buahnya terdapat warna semburat merah yang mencolok dan inilah yang membedakan dengan kultivar salak Sibetan lainnya. Ukuran buah salak Getih sedikit lebih besar dari salak Gula Pasir. Salak Getih atau disebut juga dengan nama salak Merah (Bahasa Bali: barak) ciri khasnya terletak pada daging buahnya yang sebagian besar berwarna merah mirip warna darah (Bahasa Bali: getih).

4. Salak Gula Pasir (Salacca zalacca var. Gula Pasir). Salak Gula Pasir ciri khasnya warna daging buah putih mengkilap, rasa buah manis walaupun umur buah masih muda, tidak ada rasa asam dan sepet, tidak masir, daging buahnya tebal, dan tidak melekat pada biji. Salak Gula Pasir telah dilepas sebagai varietas unggul nasional berdasarkan Keputusan Menteri Pertanian No. 584/Kpts/TP.240/7/94, tanggal 23 Juli 1994. Salak Gula Pasir merupakan salak Bali yang rasanya paling manis dan getas. Kulit buahnya coklat kehitaman, sebagaimana jenis salak Bali yang lain. Dari segi tampak luar, salak gula pasir hampir tidak ada bedanya dengan salak yang lain, tetapi perbedaannya yang mencolok jika kulit buahnya dikupas akan tampak daging buahnya yang berwarna putih mengkilap. Dibandingkan dengan Salak Pondoh, Salak Gula Pasir memiliki daging buah lebih tebal dan lebih berair dan lebih kenyal. Keistimewaan salak gula pasir ini adalah sudah terasa manis dari masih berumur muda tanpa harus menunggu sampai matang. Inilah sebabnya harga jual salak Gula Pasir bisa mencapai 4 hingga 5 kali lipat lebih mahal dari harga salak Bali lainnya.

5. Salak Injin (Salacca zalacca var. Injin). Salak Injin bentuk dan kulit buahnya mirip seperti Salak Nenas, tetapi jika dikupas daging buahnya terdapat warna hitam bergaris searah dari dasar ke ujung buah. Semakin matang buah warna hitam tersebut akan semakin banyak bahkan bisa menutup seluruh daging buah sehingga wana daging buah seperti ketan hitam. Oleh karena itulah maka nama salak injin (ketan hitam) ini diambail.

6. Salak Kelapa (Salacca zalacca var. Kelapa). Salak Kelapa atau salak Nyuh sering juga disebut dengan nama salak Penyalin atau salak Jaka memiliki ciri khas pelapah daun durinya jarang atau tidak berduri sama sekali. Kalau ada durinya, maka duri tersebut pendek-pendek dan tidak tajam. Warna kulit buahnya coklat kemerahan, bentuk buah lebih bulat dari Salak Nenas, tetapi memiliki ukuran yang sama. Dibandingkan salak Nenas, rasa buah salak Nyuh sedikit lebih sepat.

7. Salak Nangka (Salacca zalacca var. Nangka). Salak Nangka memiliki ciri khas tandan buahnya bercabang dua (Bahasa Bali: duang rence), tidak seperti kultivar salak Sibetan yang lain dimana tandan buahnya tunggal atau tidak bercabang (Bahasa Bali: a rence), kulit buahnya pada saat matang agak kehitaman, buahnya besar, agak bundar dan montok (bahasa Bali: bontok) berwarna coklat kekuningan. Warna daging buahnya kekuningan seperti warna daging buah nangka matang. Selaput tipis daging buahnya juga ada bintik-bintik kekuningan. Daging buahnya tebal dan berair. Terkadang pada daging buah terdapat warna coklat ke hitaman berbentuk garis, terdiri atas 2 sampai 3 garis. Tanda adanya garisgaris hitam pada buah salak Nangka menunjukkan buah tersebut lebih manis dan segar dibandingkan 


\section{Konservasi Plasma Nutfah Salak Sebagai Kebun Botani Untuk Mendukung Desa Sibetan Sebagai Desa Sentra Agrowisata Berbasis Salak}

buah lain yang tgidak ada garis hitamnya. Masyarakat Sibetan menyebut salak Nangka dengan daging buah bergaris-garis hitam sebagai salak Porong. Salak Nangka tergolong kultivar salak pavorit nomor dua setelah salak gula pasir, karena walaupun kualitasnya sangat disukai konsumen tetapi dari segi harga salak nangka tidak semahal salak gula pasir.

8. Salak Nenas (Salacca zalacca var. Nenas). Selak Nenas memiliki bentuk dan kulit buah yang sangat mirip dengan salak Gondok dengan warna coklat kekuningan. Bila dikupas, daging buahnya terlihat lebih putih dibandingkan salak Gondok dengan rasa lebih manis, tebal dan berair. Selain manis, buah salak Nenas juga memiliki rasa masam sehingga memiliki ciri khas daging buahnya manis bercampur asam.

9. Salak Pade (Salacca zalacca var. Pade). Salak Pade memiliki ciri khas daunnya pendek-pendek dan kecil mirip seperti salak bingin, bedanya tampilan habitusnya tidak seperti salak Bingin, tetapi layaknya seperti kultivar salak Sibetan yang lain. Perbedaan lainnya dibandingkan dengan salak Bingin adalah salak Bingin sangat jarang berbuah, tetapi salak Pade dapat berbuah seperti halnya salak Sibetan lainnya.

10. Salak Penyalin (Salacca zalacca var. Penyalin). Salak Penyalin bila dibandingkan dengan kultivar salak Sibetan yang lain memiliki pelepah daun yang lebih besar dengan duri yang sangat jarang. Kalaupun ada durinya, maka duri tersebut pendek-pendek dan tidak tajam. Buahnya mirip dengan salak Kelapa tetapi rasa buahnya lebih sepat.

11. Salak Turis/Mangku (Salacca zalacca var. Turis). Salak Turis atau disebut juga dengan nama salak Mangku memiliki ciri khas sesuai dengan namanya yaitu kulit buahnya sejak masih muda berwarna putih kekuningan mirip seperti warna kulit wisatawan asing (turis). Selain ciri spesifik pada warna kulit buah, ciri-ciri yang lain dari salak Mangku seperti bentuk pohon, daun, bunga, daging buah, dan lain-lain, sama seperti halnya salak Bali yang lain. Ukuran buahnya mirip seperti ukuran Salak Bali pada umumnya, namun warna kulitnya putik kekuningan seperti halnya kulit bule sehingga disebut sebagai Salak Gading ataupun Salak Bule. Rasa buahnyapun kurang manis bahkan bisa dibilang masam.

12. Salak Sudamala (Salacca zalacca var. Sudamala). Salak Sudamala memiliki ciri spesifik yaitu anak daunnya bergaris-garis kuning sejajar kearah memanjang daun. Ciri-ciri lainnya secara morfologi mirip seperti kultivar salak Sibetan yang lain seperti salak Gondok, salak Nangka, salak Nenas dan lain-lain, tetapi kkhasannya adalah daunnya bergaris-garis kuning dan sangat jarang berbuah.

Asal-usul tanaman salak di Sibetan tidak ada catatan secara jelas, tetapi menurut Hutton (1996), salak yang dibudidayakan di Sibetan, Karangasem, merupakan buah salak yang paling digemari oleh konsumen dibandingkan dengan salak produksi lainnya di Asia. Menurut Ashari (2004), tanaman salak berasal dari daerah di kawasan Asia Tenggara, dan umumnya dibudidayakan secara komersial di Indonesia, di samping juga di Malaysia dan Thailand.

Kultivar salak yang ditemukan di Desa Sibetan tergolong tanaman berumah satu (monoecious), yaitu dalam satu bunga tedapat kelamin jantan dan betina, sehingga tanpa perlu disilangkan sudah dapat menghasilkan buah dengan baik. Sifat tersebut berbeda dengan salak yang pada umumnya ditanam di provinsi lainnya di Indonesia yang berumah dua (dioecious), yaitu bunga jantan dan betina terpisah dalam pohon yang berbeda, sehingga agar diperoleh hasil buah yang memuaskan maka perlu disilangkan atau dikawinkan dalam waktu yang tepat (Moncur dan Watson, 1987; Mogea, 1990; Hartana et al., 2002). Dengan keunggulan dari salak Sibetan dalam kemampuannya menyerbuk sendiri (kleistogamy) atau buah dihasilkan dengan penyerbukan alami, memberikan kemudahan yang luar biasa dalam membudidayakan, yaitu tidak memerlukan curahan tenaga kerja untuk mengawinkan dan dapat dengan mudah dikembangkan dengan menggunakan biji, karena biji yang dihasilkan sama dengan induknya. Oleh karena itu, biaya produksi dalam membudidayakannya jauh lebih murah dibandingkan biaya produksi dalam budidaya salak lainnya sehingga daya saing pasarnya akan lebih tinggi dan kompetitif (Rai et al., 2016a).

Kultivar-kultivar salak yang ditemukan di Sibetan dikoleksi dengan mengambil bijinya untuk bahan perbanyakan. Proses pembuatan bibit berlangsung lancar dan sukses, terbukti dari $100 \%$ biji yang ditanam berhasil menjadi bibit sehingga dihasilkannya 1500 bibit salak dari 11 kultivar salak. Satu kultivar yaitu salak Bingin tidak dapat diperbanyak karena selama pengabdian tidak berbuah, dan perbanyakan secara vegetatif dengan cangkokan juga tidak dapat dilakukan karena tidak tersedia anakan. Pelaksanaan perbanyakan dan koleksi 11 kultivar salak yang dilakukan dengan metode bekerja sambil belajar melalui pelatihan dan transfer teknologi diikuti dengan baik dan antusias oleh peserta, mulai dari penyampaian hasil identifikasi kultivar, pemilihan dan koleksi buah yang baik sebagai sumber biji/benih, penyemaian benih, penyiapan rumah paranet, penyiapan media tanam, penanaman benih pada media tanam, dan pemeliharaan bibit sampai siap tanam. Baik pada sesi penjelasan maupun sesi praktek tahap-tahap pembuatan bibit, peserta pelatihan mengikuti 
dengan serius yang ditunjukkan dengan pengajuan berbagai pertanyaan dan tanggapan, melakukan semua kegiatan dengan semangat, serta memperbandingkan metode yang disampaikan instruktur (tim pengabdian) dengan metode yang biasa mereka lakukan sebelumnya, yang menunjukkan keseriusan mereka sangat tinggi.

Keberhasilan pelaksanaan pembuatan bibit tercermin juga dari bibit yang dihasilkan tumbuh sehat dan vigor (Gambar 1) dan jawaban peserta dari kuesioner yang diberikan saat kegiatan berlangsung yang semuanya (20 orang responden) menyatakan sangat puas sampai puas. Jumlah peserta yang menyatakan sangat puas dan puas ketika ditanyakan tentang pelaksanaan kegiatan pelatihan dan transfer teknologi pembuatan bibit salak adalah $90 \%$ dan $10 \%$, yang berarti tidak ada (0\%) responden yang menyatakan kurang puas atau sangat tidak puas. Kepuasan yang lebih tinggi lagi diberikan oleh peserta mengenai materi pelatihan dan metode/cara pelatih/instruktur dalam memberikan pelatihan yang dijawab sangat puas oleh $95 \%$ dan puas oleh $5 \%$ responden, serta kepuasan terhadap hasil pembibitan salak yang dijawab sangat puas oleh $100 \%$ responden.
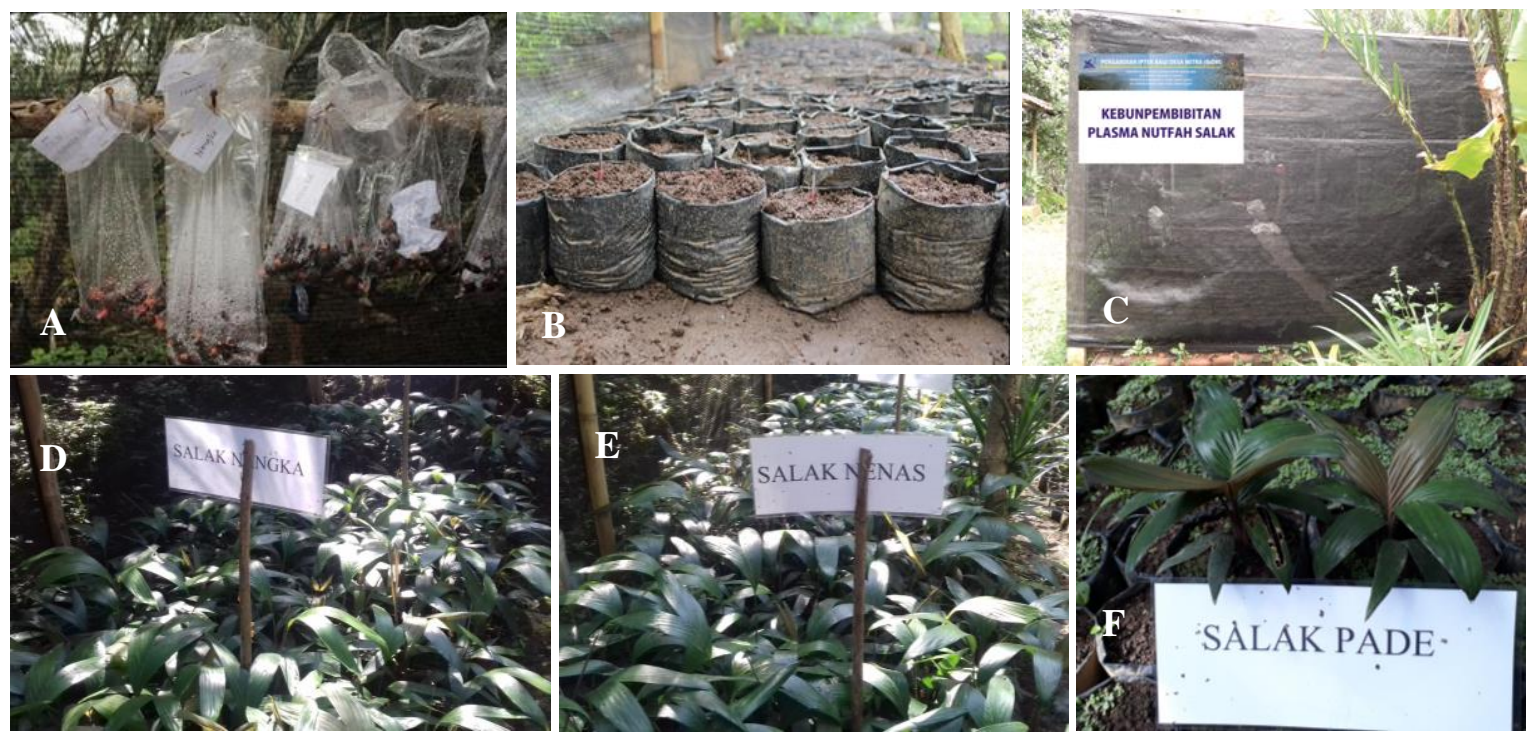

Gambar 1. Proses pembibitan dan bibit salak yang dihasilkan. Biji yang baru diambil dari buah salak dikecambahkan dengan menggantung biji tersebut pada kantong plastik (A), plibag yang telah ditanami hasil semaian biji (B), rumah paranet sebagai rumah pembibitan (C), bibit hasil perbanyakan kultivar salak Nangka (D), bibit hasil perbanyakan kultivar salak Nenas (E), dan bibit hasil perbanyakan kultivar salak Pade (F).

Penanaman 1500 bibit yang dihasilkan sebagai Kebun Botani Plasma Nutfah (Arboretum) dilakukan pada lahan/kebun salak yang sudah berumur tua. Hal tersebut dilakukan karena kesulitan mencari lahan kosong sebagai lokasi arboretum agar bisa dengan mudah dapat diakses untuk digunakan sebagai obyek agrowisata. Lahan terpilih merupakan hasil kesepakatan masyarakat dengan pertimbangan letaknya strategis dengan pemandangan yang indah (nice view) dan mudah diakses dari berbagai arah. Nantinya setelah bibit yang ditanam mulai tumbuh dewasa, tanaman salak tua yang pada saat penanaman masih berproduksi dan sekaligus befungsi sebagai penaung tanaman muda di bawahnya, akan dibongkar sehingga kumpulan 11 kultivar salak Sibetan yang ditanam tidak tercampur lagi dengan tanaman tua.

Pelaksanaan penanaman dan pemeliharaan dengan menerapkan Good Agricultural Practices/GAP berlangsung lancar dan diikuti dengan antusias oleh peserta. Tahapan proses penanaman bibit meliputi penentuan jarak tanam, penyiapan lubang tanam, pemberian pupuk dasar, penanaman bibit, pemasangan ajir untuk pengamanan bibit agar terhindar secara fisik dari gangguan orang atau binantang, dan pemasangan label agar jenis kultivar mudah dikenali. Sedangkan pemeliharaan meliputi pembumbunan dan penggemburan tanah di sekitar tanaman, pemupukan secara berkala, pengaturan dan pemangkasan pohon penaung, pengendalian gulma, pengendalian hama dan penyakit, pemangkasan pelepah daun, dan pengairan. Khusus untuk kegiatan pengairan, karena lokasi arboretum di lahan tegalan yang jauh dari sumber air maka untuk menjamin agar pertumbuhan dan perkembangan jenis-jenis plasma nutfah salak di kebun Arboretum dapat berkembang dan berproduksi dengan baik maka diperlukan adanya intalasi irigasi agar pengairan tidak tergantung dari air hujan. Untuk itu, dilakukan pemasangan instalasi irigasi tets dengan pemipaan. Air dipanen dengan 


\section{Konservasi Plasma Nutfah Salak Sebagai Kebun Botani Untuk Mendukung Desa Sibetan Sebagai Desa Sentra Agrowisata Berbasis Salak}

menggunakan terpal, kemudian dialirkan ke bak plastik besar. Dari bak plastik besar, air dibagi dan disistribusikan dengan sistem pemipaaan ke pohon-pohon tanaman salak di kebun Arboretum. Contoh hasil penanaman bibit dan instalasi iriasi tetes seperti pada Gambar 2.

Kebun botani plasma nutfah salak yang dibuat melalui kegiatan ini dirancang tidak hanya sebagai kebun koleksi dan konservasi, tetapi sekaligus ditata manjadi obyek agrowisata. Jenis-jenis salak dalam arboretum diberikan nama, penjelasan secara botani, morfologi, agronomi dan informasi lainnya yang berguna bagi pengunjung. Namun demikian, kedepan berbagai informasi terkait dengan kebun botani plasma nutfah perlu dirangkum dan dikompilasi menjadi buku sumberdaya genetik palsama nutfah salak Sibetan sehingga dapat digunakan sebagai bahan informasi dan edukasi yang komprehensif bagi wisatawan yang berkunjung. Adanya arboretum diharapkan dapat menambah variasi kunjungan di Desa Sibetan, karena sebelumnya menurut Rai et al. (2018), berbagai produk olahan berbahan baku salak telah berhasil dikembangkan oleh Kelompok Wanita Tani Desa Sibetan yaitu kulit buah salak menjadi teh salak, biji salak menjadi kopi salak, buah salak yang tidak laku terjual menjadi kurma salak, madu salak dan pia salak, serta rebung salak (pangkasan anakan salak) menjadi kare salak dan tumis salak.

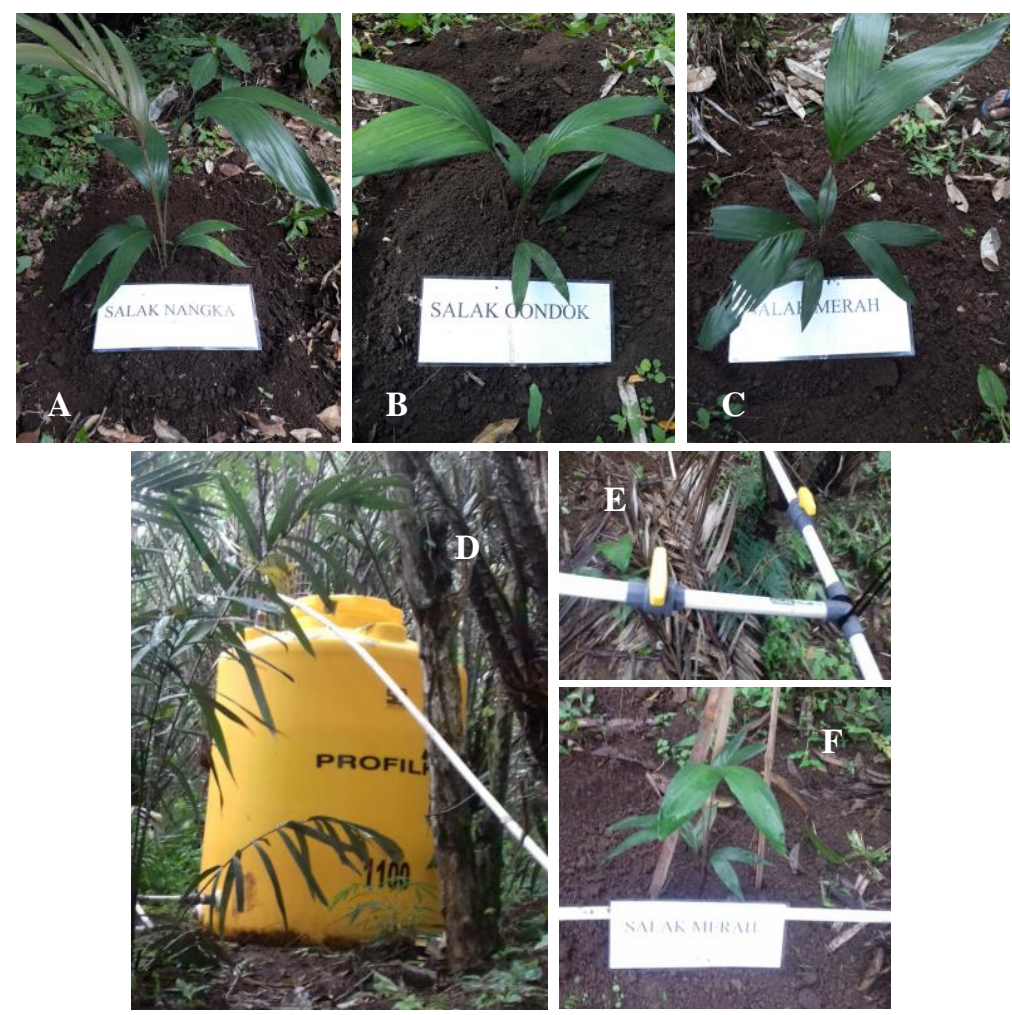

Gambar 2. Penananam bibit dan instalasi irigasi tetes untuk pengairan pada Arboretum. Bibit salak Nangka yang baru ditanam (A), Bibit salak Gondok yang baru ditanam (B), Bibit salak Pade yang baru ditanam (C), Bak plastik besar untuk penampung air (D), instalasi pipa distribusi air (E), dan pipa dengan nosel penetes air pada masing-masing pohon bibit yang baru ditanam $(\mathrm{F})$.

\section{DAFTAR PUSTAKA}

Annisa, A. Mardliyyah, J. Kusmoro, J. Iskandar. 2017. Keragaman morfologi dan genetik bambu di Arboretum Universitas Padjadjaran, Sumedang, Jawa Barat. Prosiding Seminar Nasional Masyarakat Biodiversitas Indonesia 3(3):351-360. DOI: 10.13057/psnmbi/m030311

Annisaurrohmah, W. Herawati, P. Widodo. 2014. Keanekaragaman kultivar salak Pondoh di Banjarnegara. Biosfera 31 (2):71-83. 
Ariestin, Y., Kuswanto, S. Ashari. 2015. Keragaman jenis salak bangkalan (Salacca Zalacca (Gaertner) Voss) menggunakan penanda morfologi dan analisis isozim. Jurnal Produksi Tanaman 3(1):35 - 42.

Ashari, S. 2004. Biologi reproduksi tanaman buah-buahan komersial. Penerbit: Bayumedia Publishing, Malang. 201p.

Asosiasi Wisata Agro Indonesia. 2004. Pengertian dasar wisata agro. Makalah disampaikan dalam pelatihan wisata agro. Yogyakarta,15-19 Juli 2004. Yogyakarta.

Badan Pusat Statistik (BPS) Provinsi Bali. 2018. Bali dalam Angka 2018. Badan Pusat Statistik Provinsi Bali Tahun 2018.

Departemen Pertanian. 2008. Strategi pengembangan wisata agro di Indonesia. http:// database.deptan.go.id/agrowisata. [18 Januari 2009

Goodwin, H. 1998. Sustainable tourism and poperty elimination. Peper: Workshop on Sustainable Tourism and Poperty. United Kingdom.

Hartana, A., J.P. Mogea, A.A.K. Darmadi. 2002. Pembungaan salak Bali. Hayati Journal of Bioscienses 9(2):59-61.

Hutton, W. 1996. Tropical fruits of Indonesia. Periplus Editions, Singapore. 62p

Mogea, J.P., D. Gandawidjaja, H. Wiriadinata, R.E.Nasution, Irawati. 2001. Tumbuhan langka Indonesia. LIPI-Seri Panduan Lapangan. Bogor. Balai Penelitian Botani, Puslitbang Biologi, LIPI.

Moncur, M.W., B.J. Watson. 1987. Observations on The floral biology of the monoecious form of Salacca Zalacca 31 (1):20-22.

Nandini, N.; N. Shiddamallayya. 2015. Conservation of wild and cultivated fruits resources of Bangalore urban. Species, 12(35):87-91.

Napolion, H., E. Sribudiani, T. Arlita. 2015. Pemahaman pengunjung terhadap arti dan fungsi arboretum Universitas Riau. Jurnal Online Mahasiswa Faperta Riau 2(2):15-21.

Pulakiang, A.R.; J.S. Polii-Mandang, S. Sompotan. 2017. Beberapa karakter morfologis tanaman salak (Salacca Zalacca (Gaert) Voss) di Kampung Bawoleu, Kecamatan Tagulandang Utara, Kabupaten Kepulauan Siau. Eugenia 23(2): 48-57.

Purnomo, D.W., S.M. Solihah, Sumanto. 2015. Nilai konservasi dan jasa lingkungan koleksi tumbuhan kebun raya pada kawasan perkotaan. Prosiding Seminar Nasional Masyarakat Biodiversitas Indonesia 1(8):1851-1855. Doi: 10.13057/Psnmbi/M010817.

Rai, I.N., G. Wijana, P. Sudana, W. Wiaatmaja, C.G.A. Semarajaya. 2016a. Buah-buahan lokal Bali: Jenis, pemanfatan, dan potensi pengembangannya. Penerbit: Palawa Sari, Denpasar. ISBN: 978-602-840946-9. 286 hal.

Rai, I.N., G. Wijana, I.P. Sudana, I.W. Wiraatmaja, C.G.A. Semarajaya, N.K. Alit Astiari. 2016b. Identifikasi dan telaah pemanfaatan sumber daya genetik buah-buahan lokal untuk meningkatkan integrasi pertanian dan pariwisata di Bali. Jurnal Hortikultura Indonesia 7(1): 31-39.

Rai, I.N., I.P. Sudana, C.G.A. Semarajaya, I.W. Wiraatmaja. 2017. Pengembangan agrowisata Desa Buahan Kaja melalui identifikasi potensi, pengemasan paket wisata, dan pelatihan sumberdaya manusia. Jurnal Udayana Mengabdi 16(1):38-45.

Rai, I.N.; I.P. Sudana, W. Wiraatmaja, M. Sukewijaya. 2018. Penataan kebun dan pembuatan kuliner dari buah dan rebung Salak untuk mendukung pengembangan Desa Sibetan sebagai desa sentra agrowisata berbasis salak. Jurnal Udayana Mengabdi 17(2):57-66.

Subbaraya, U. 2006. Farmers' knowledge of wild musa in India. Food and Agriculture Organization of the United Nations, Rome. 50 pp.

Sumarwoto, J. 1990. Pengembangan agrowisata: potensi dan prospek. seminar nasional: pembangunan pertanian dan pedesaan Sumatera. Berastagi, 5-8 Maret.

Suskendriyati, H, A. Wijayati, N. Hidayah, D. Cahyuningdari. 2000. Studi morfologi dan hubungan kekerabatan varietas Salak Pondoh (Salacca zalacca (Gaert.) Voss.) di dataran tinggi Sleman. Biodiversotas 1(2): 59 - 64. 
Konservasi Plasma Nutfah Salak Sebagai Kebun Botani Untuk Mendukung Desa Sibetan Sebagai Desa Sentra Agrowisata Berbasis Salak

Yudohartono, T.P. 2008. Peranan taman hutan raya dalam konservasi sumberdaya genetik: peluang dan tantangannya. Informasi Teknis 6(2):1-6. 